\title{
Ação profissional e subjetividade: para além do conceito de intervenção profissional na psicologia
}

\author{
Professional action and subjectivity: beyond the concept of \\ professional intervention in psychology
Acción profesional y subjetividad: más allá del concepto de intervención profesional en psicología

\author{
FERNANDO GONZÁLEZ REY* \\ DANIEL MAGALHÃES GOULART** \\ MARÍlIA DOS SANTOS BEZERRA****
}

\begin{abstract}
RESUMO
O presente artigo visa apresentar e discutir possibilidades de sistemas de ações profissionais a partir da teoria da subjetividade em uma perspectiva cultural-histórica, de modo a avançar sobre temas e práticas historicamente ausentes na psicologia soviética. Para tanto, são discutidas ações profissionais em diferentes contextos, a saber, na psicoterapia, nas práticas escolares, na atuação em instituições de saúde e na comunidade. Essa proposta teórica implica uma concepção dialógica e não instrumental dos sistemas de ações profissionais e atribui uma forte importância à capacidade dos indivíduos e grupos de se posicionarem de forma ativa em seus diversos caminhos de vida, emergindo como sujeitos de suas próprias experiências. Nesse sentido, as práticas profissionais devem ser orientadas a favorecer o desenvolvimento humano, para além da resolução pontual de problemas específicos.
\end{abstract}

Palavras-chave: Psicologia do desenvolvimento. Psicoterapia. Inclusão educacional. Assistência à saúde. Ação comunitária.

\begin{abstract}
This article intends to present and discuss possibilities of professional action systems through the theory of subjectivity in a cultural-historical perspective. This in order to develop on issues and practices historically absent in Soviet psychology. The professional actions are discussed in different contexts, such as: in psychotherapy, in schools, in health care services and in the community. This theoretical proposal employs a dialogical and noneinstrumental perspective of professional action systems. In addition addresses the strong importance of the ability of individuals and groups to position themselves actively in their various life trajectories, emerging as subjects of their own experiences. In this sense, professional practices should be targeted to promote human development, beyond the punctual resolution of specific problems.
\end{abstract}

Keywords: Developmental psychology. Psychotherapy. Educational inclusion. Health care. Community action.

\section{RESUMEN}

El presente artículo presenta y discute las posibilidades de sistemas de acción profesional a partir de la teoría de la subjetividad en una perspectiva cultural-histórica, que permita avanzar sobre temas y prácticas históricamente ausentes en la psicología soviética. Con ese objetivo, son discutidas acciones profesionales en diferentes contextos: en la psicoterapia, en las prácticas escolares, en la actuación en instituciones de salud y en la comunidad. Esta propuesta teórica implica una concepción dialógica y no instrumental de los sistemas de acción profesional y atribuye gran importancia a la capacidad de los individuos y grupos de asumir posiciones de forma activa en sus diferentes caminos de vida, emergiendo como sujetos de sus propias experiencias. En este sentido, las prácticas profesionales deben estar orientadas a favorecer el desarrollo humano, más allá de la resolución particular de problemas específicos.

Palabras claves: Psicología del desarrollo. Psicoterapia. Inclusión educacional. Asistencia en saúde. Acción comunitaria.

\footnotetext{
* Doutor em Psicologia. Professor titular da Faculdade de Ciências da Educação e da Saúde do Centro Universitário de Brasília (FACES/UniCEUB). Professor Sênior do Programa de Pós-Graduação em Educação da Universidade de Brasília (PPGE/UnB). E-mail: <gonzalez_rey49@hotmail.com>.

** Mestre em Educação. Professor associado da Faculdade de Ciências da Educação e da Saúde do Centro Universitário de Brasília (FACES/UniCEUB). Doutorando do Programa de Pós-Graduação em Educação da Universidade de Brasília (PPGE/UnB/CAPES).E-mail: < danielgoulartbr@gmail.com>.

*** Mestre em Educação. Professora associada do Instituto de Ensino Superior de Brasília (IESB). Doutorando do Programa de Pós-Graduação em Educação da Universidade de Brasília (PPGE/UnB). E-mail: <mariliasonho@gmail.com>.
} 


\section{INTRODUÇÃO}

$\mathrm{O}$ enfoque cultural-histórico, tradicionalmente associado à teoria cultural-histórica de Vygotsky, embora tal designação não tenha sido usada pelo próprio autor (YASNITSKY, 2009, 2012), é tratado neste artigo como um posicionamento teórico que caracterizou a psicologia soviética em suas diferentes tendências, tendo como caraterística essencial a definição cultural e histórica da gênese do psiquismo humano. Porém, essas diferentes tendências expressaram importantes discrepâncias entre si, no que concerne ao foco de seus estudos. Após a morte de Vygotsky, a escola mais poderosa de Moscou centrou-se no estudo da atividade, definindo as funções psicológicas como formas internas de atividade (LEONTIEV, 1975). Rubinstein e seu grupo, por outro lado, enfatizaram o estudo da organização psicológica da consciência e da personalidade; enquanto os representantes da escola de Leningrado (sobretudo, Ananiev e Miasichev), definiram o foco de seus trabalhos no estudo da personalidade, da comunicação e das instituições sociais.

Entretanto, tais distintas tendências não foram estáticas e não se excluíram mutuamente, mas mantiveram relações diretas e indiretas, como por exemplo, no caso do convite de Rubinstein a Vygotsky para ocupar a cátedra deixada por Basov no Instituto Pedagógico Hertzen de Leningrado. Os últimos trabalhos de Vygotsky foram orientados ao desenvolvimento de uma teoria da consciência, tema que o aproximou mais de Rubinstein do que de seu próprio grupo de discípulos, naquele momento agrupado em Kharkov sob a liderança de A. N. Leontiev.

Esse mosaico de posições psicológicas diversas teve em comum, no entanto, uma prática mais orientada à pesquisa do que à prática profissional. $\mathrm{O}$ tema do social era delicado no Estado Soviético, pois a representação do social nessa época respondia mais a um estereotipo ideológico dominante do que a uma representação orientada a compreender a sociedade em seus processos contraditórios e de mudança. Esse fator foi decisivo na ausência de uma psicologia social forte, bem como no parco desenvolvimento de sistemas de ações profissionais ${ }^{1}$ orientados às instituições sociais e comunitárias de forma geral. Essa situação culminou num quadro, no qual processos sociais e institucionais relacionados com as práticas em saúde e educação fossem ignorados pela psicologia soviética.

Embora o próprio Vygotsky tenha desenvolvido uma prática interessante e inovadora na área da "defectologia" e, já nos momentos finais de sua vida, na intervenção

\footnotetext{
${ }^{1}$ Neste artigo preferimos usar o termo "sistema de ações profissionais" ao invés de "intervenção", devido ao caráter diretivo, unilateral e pouco participativo das práticas associadas com a intervenção psicológica nas diferentes áreas da psicologia.
}

clínica em pacientes portadores de transtornos crônicos, nos quais se relacionou estreitamente com Luria e com as discípulas de Lewin, tais como Dembo e Zeigarnik, Bozhovich foi a única entre seus discípulos a se orientar ao estudo da personalidade. No estudo desse tema, a autora desenvolveu ampla prática profissional na escola, junto a seu grupo de pesquisa (Konnikova, Slavina, Neimark, Chudnovsky, entre outros), trabalhando com crianças e adolescentes com problemas sociais e de conduta. De modo geral, os sistemas de ações profissionais na perspectiva cultural-histórica se concentraram na escola e em hospitais com pacientes crônicos na psicologia soviética. Somente a escola de Leningrado tomou um caminho diferente.

Em Leningrado, sob a direção de Miasichev, foram desenvolvidos interessantes processos de ação profissional nas instituições, tendo sido o único grupo dentro da psicologia soviética, que, na década de 1950 e 1960, avançou no estudo de transtornos mentais associados aos problemas sociais (MIASICHEV, 1960). Não obstante, a prática não foi de fato o ponto forte da psicologia soviética. Todo tipo de ação profissional deveria ser antes aprovado pelo Estado, correndo o risco de ser acusado de "ideologicamente problemático". Sobre isso, Vasilyuk escreve:

\begin{abstract}
As mudanças radicais que começaram na Psicologia Russa nos anos 80 demandaram uma especial análise metodológica (Vasilyuk, 1992). A aparição dos primeiros centros psicológicos marcou o nascimento de uma prática psicológica independente. É difícil superestimar a significação histórica desse evento: a psicologia adquiriu seu corpo nos centros de aconselhamento. Esses centros tiveram a mesma significação para a psicologia do que as escolas para a pedagogia, as igrejas para as religiões e as clinicas para a medicina (VASILYUK, 2015, p. 2).
\end{abstract}

Entretanto, Vasilyuk omite que esses centros passaram a ser privados, aos quais grande parte da população russa não tinha acesso. Assim, no socialismo de Estado, as práticas da psicologia foram extremamente restritas, devido ao monopólio do controle pelo Estado sobre todo tipo de contradições e conflitos sociais. Com a instauração do capitalismo acrítico e sem direitos na Rússia, serviços psicológicos foram instalados, mas somente para atender às elites russas.

No Ocidente, os trabalhos desenvolvidos na linha de Vygotsky avançaram essencialmente em práticas profissionais orientadas ao espaço escolar (FLEER, 2011, 2012; DANIELS, 2012; HEDEGAARD, 2012; PORTES, 2011; MOLL, 2011), embora Portes e Moll também tenham desenvolvido interessantes trabalhos com comunidades pobres e de imigrantes nos Estados Unidos. 
Nesse contexto, o presente artigo tem como objetivo apresentar e discutir possibilidades de sistemas de ações profissionais a partir da teoria da subjetividade em uma perspectiva cultural-histórica, de modo a avançar sobre temas e práticas historicamente ausentes na psicologia soviética (GONZÁLEZ REY, 1997, 2000, 2002, 2005, 2007, 2011, 2012, 2014; MITJÁNS MARTÍNEZ, 1999, 2005, 2009).

\section{A SUBJETIVIDADE: BASES PARA NOVAS FORMAS DE AÇÃO PROFISSIONAL EM DISTINTAS ESFERAS DA VIDA SOCIAL}

A definição da subjetividade se apresenta através de categorias capazes de expressar, na unidade simbólicoemocional, a mobilidade e diversidade da experiência dos indivíduos e dos grupos sociais. É essa unidade simbólicoemocional que define ontologicamente os fenômenos significados como subjetivos. Tal unidade caracteriza os sentidos subjetivos, que representam um processo constante que define a qualidade da experiência vivida: não são os fatos concretos que definem tal qualidade, mas as produções subjetivas, tanto individuais como sociais, que emergem no curso de uma experiência humana. Entre os fatos objetivos de uma experiência vivida e seus sentidos subjetivos, não existem relações diretas nem lineares. Ambas as dimensões da subjetividade, social e individual, integram-se reciprocamente e de forma recursiva nas configurações subjetivas sociais e individuais.

Nessa perspectiva, ações profissionais orientadas à mudança e ao desenvolvimento de pessoas e instituições devem integrar ambos os níveis da subjetividade em seus objetivos. Ainda hoje, as práticas no campo da psicologia estão orientadas principalmente a objetivos associados a mudanças individuais e grupais restritas, de modo a não abarcarem os processos das instituições e das sociedades dentro dos quais os comportamentos dos indivíduos e grupos acontecem. Por outro lado, a proposta teórica da subjetividade implica uma concepção dialógica e não instrumental dos sistemas de ações profissionais, atribuindo central importância à capacidade dos indivíduos e grupos de se posicionarem de forma ativa em seus diversos caminhos de vida, emergindo como sujeitos de suas próprias práticas.

Segundo essa proposta, a subjetividade não representa uma estrutura intrapsíquica individual que determina o comportamento, mas representa uma qualidade que especifica os processos humanos nas condições da cultura. Um princípio essencial dessa formulação teórica é seu caráter gerador. A subjetividade é uma produção singular que caracteriza a experiência vivida. Nesse sentido, tanto indivíduos como grupos existem em redes relacionais vivas em cada um dos momentos concretos de uma ação, por meio da articulação de sentidos subjetivos e configurações subjetivas que se implicam estreitamente nesse momento. Porém, os indivíduos e grupos não expressam de forma imediata e direta as configurações subjetivas de suas ações, pois elas não representam um a priori da ação, mas um processo que é constituído pela ação e que, simultaneamente é constituinte dela. Devido a essa processualidade da subjetividade humana, as decisões, posições e caminhos que os indivíduos e grupos tomam no curso de suas ações constituem novos processos de produção subjetiva.

As configurações subjetivas são formações dinâmicas, que expressam sua estabilidade pela congruência dos sentidos subjetivos que elas geram, não pela identidade desses sentidos subjetivos. Não existem sentidos subjetivos iguais nos contextos diferentes da ação humana. Essa estabilidade em processo é passível de mudanças e rupturas imprevisíveis no próprio curso da ação, o que é condição para novos caminhos de desenvolvimento subjetivo. Em tais processos de mudanças e rupturas, a emergência do sujeito individual e social é essencial.

O que implica esta definição da subjetividade na compreensão dos sistemas de ações profissionais?

1. O caráter dialógico e não diretivo das ações profissionais. O profissional é um facilitador, um provocador, para que emerja o diálogo em uma prática profissional. Os comportamentos que emergem no diálogo não representam posições previstas. Com frequência, eles são contraditórios, geradores de conflitos e associados a comportamentos que podem parecer antes um retrocesso que um avanço.

2. A ausência de respostas e mudanças em tempos breves. As pessoas amadurecem suas reflexões, a partir dos novos sentidos subjetivos que as ações profissionais vão gerando. Esse processo, em geral, implica desafios frente aos quais as pessoas precisam se posicionar e do qual os profissionais devem participar como interlocutores, não como provedores de um caminho supostamente certo.

3. Ações profissionais voltadas para que novas configurações subjetivas emerjam, de modo que as pessoas possam se posicionar de forma ativa, como sujeitos de suas experiências. Entretanto, a mudança não implica a garantia de estabilidade desse novo processo. Por isso, devemos acompanhar por certo tempo o curso da mudança, até termos elementos que sustentem a hipótese de que esse novo caminho esteja efetivamente em desenvolvimento. 


\section{DIFERENTES SISTEMAS DE AÇÕES PROFISSIONAIS DESENVOLVIDOS A PARTIR DO REFERENCIAL DA SUBJETIVIDADE EM UMA PERSPECTIVA CULTURAL-HISTÓRICA}

\section{A ação profissional na psicoterapia. Formas e usos da psicoterapia em diferentes contextos de ação profissional}

Historicamente, a psicoterapia tem sido associada ao trabalho clínico em consultório, o que nos remete tanto à origem médica dos pioneiros de sua institucionalização, como à subjetividade social dominante no mundo de consumo - expressão de um capitalismo mundial cada vez mais agressivo. Entretanto, a psicoterapia é uma prática importante nas mais diversas formas de ação profissional orientadas à mudança do outro.

Em nossa linha de pesquisa sobre o estudo da subjetividade na saúde e na educação, a pesquisa é inseparável das práticas profissionais dentro das instituições às quais se remetem (BEZERRA, 2014; GOULART, 2013, 2015; ROSSATO, 2009). Essa linha começou com nossos trabalhos com pessoas com hipertensão e infarto do miocárdio em Cuba (GONZÁLEZ REY, 1990, 1993). Nessas pesquisas, o trabalho psicoterapêutico se desenvolvia simultaneamente de forma individual e grupal. As ações terapêuticas constituídas nesses espaços estavam orientadas a mudar a relação das pessoas com o uso de seu tempo pessoal e com o sistema de atividades cotidianas que caracterizavam seus modos de vida.

Esse trabalho nos levou a compreender a importância do acompanhamento dessas pessoas para além do consultório, constituindo relações dialógicas e que apoiassem a construção e realização de seus projetos pessoais. O planejamento conjunto das atividades a serem realizadas implica que o trabalho seja construído na dimensão de seu acontecer cotidiano, promovendo novas formas de se relacionar com o tempo, com os outros e com o mundo de forma geral - o que pode facilitar a emergência de novas reflexões sobre a vida pessoal. Nessa perspectiva, a psicoterapia deve ter como objetivo não apenas a eliminação dos sintomas, mas a preparação da pessoa para se integrar ao complexo contexto da vida cotidiana, o que está estreitamente relacionando à educação e à promoção do desenvolvimento subjetivo. É nesse processo que as rígidas configurações subjetivas associadas a estados subjetivos invariáveis e que implicam sofrimento e eventuais sintomas entram em processo de mudança.

Já em 1993, a definição da relação intrínseca entre psicoterapia e educação foi construída. Naquele momento, tal compreensão se dava da seguinte forma: “(...) a psicoterapia se diferencia das outras relações humanas, pela sua finalidade, a qual, num sentido mais geral, é a educação das pessoas implicadas nesse processo" (GONZÁLEZ REY, 1993). Tal articulação entre educação e psicoterapia era possível em Cuba nesse momento, sobretudo, porque a saúde não era privatizada - algo que começa a se modificar no contexto cubano atual.

Nos trabalhos de Bezerra (2014) e Goulart (2013, 2015), essa articulação foi recuperada e desenvolvida no contexto brasileiro atual. No primeiro caso, a autora desenvolve um trabalho, tanto dentro do espaço da escola, como fora dela, com crianças diagnosticadas com Transtorno de Déficit de Atenção com Hiperatividade (TDAH) e outros transtornos associados com as dificuldades de aprendizagem. No trabalho de Goulart, o foco está em pessoas com transtornos mentais atendidas por um Centro de Atenção Psicossocial (CAPS). Goulart também trabalha com pessoas dentro e fora da instituição, apoiando os participantes em atividades que, gradualmente, vão gerando novas ações que implicam várias áreas de suas vidas, não apenas aquelas que são o foco de sua ação profissional. Ambas as pesquisas combinam, de fato, ações terapêuticas e educativas que se articulam de forma efetiva no cenário dentro do qual as pessoas desenvolvem suas atividades. Os resultados de ambas as pesquisas são profundamente estimulantes parta o avanço de processos terapêuticos e educativos em que o foco do trabalho é a pessoa em sua integralidade, não apenas o transtorno.

A modificação terapêutica, a partir do posicionamento teórico defendido neste artigo, é o resultado da produção de novas configurações subjetivas que permitem aos indivíduos caminhos alternativos em relação ao círculo vicioso representado por comportamentos que geram mal-estar. Não se trata, portanto, do acesso às "causas objetivas" do conflito, mas de novas produções subjetivas no curso de seus caminhos de vida; daí a importância de a psicoterapia se inserir na forma de viver.

O que caracteriza nossa definição de psicoterapia é seu caráter dialógico, sendo o diálogo conduzido por hipóteses sobre a configuração subjetiva dos transtornos expressos pelos indivíduos em atendimento. $\mathrm{O}$ objetivo da psicoterapia é que o indivíduo se torne sujeito de sua experiência no curso desse processo e seja capaz de gerar processos de desenvolvimento subjetivo. As hipóteses que orientam o terapeuta não irão explicar a mudança, como pretendeu Freud e muitos dos psicoterapeutas modernos, mas constituem-se em instrumentos para facilitar a emergência do sujeito e o empreendimento de novos caminhos de vida, cujas caraterísticas e desdobramentos estarão para além da intenção e do controle do terapeuta.

A psicoterapia, nessa perspectiva teórica, está aberta a inúmeros processos que devem ganhar inteligibilidade no curso do próprio processo terapêutico. Desse modo, 
as teorias representam sistemas de inteligibilidade facilitadores de novas construções teóricas e não referências universais a priori para significar aquilo que emerge na prática. Essa premissa ganha cada vez mais espaço nos novos desafios que implica a prática profissional nas condições atuais. Por exemplo, a psicanalista argentina S. Bleichmar, analisando o tema das catástrofes sociais, que, aliás, não formou parte de nenhuma das teorias clássicas da psicologia no século XX, escreve: “(...) o traumático não é puro desvio do determinado, mas abertura a processos inéditos, o que obriga a instrumentação de fórmulas, que poderíamos chamar de não clássicas, de intervenção (BLEICHMAR, 2003, p. 37).

O conceito de configuração subjetiva tem como valor heurístico central o fato de reformular de forma radical a noção de mente como aparelho psíquico endógeno, onde o externo é considerado apenas como desencadeante de algum tipo de "pré-formado endo-psíquico" (BLEICHMAR, 2003). A configuração subjetiva expressa uma ontologia diferente a de outros domínios da realidade, na medida em que designa a organização simbólico-emocional que definem os sentidos subjetivos das experiências vividas. De forma alguma isso nega que, perante situações limites, como são as próprias catástrofes sociais, as alternativas de subjetivação do vivido se reduzam drasticamente.

Por outro lado, a proposta da subjetividade numa perspectiva cultural-histórica resgata a aspecto ativo e gerador do sujeito como processo, no qual a unidade simbólico-emocional forma uma nova qualidade, atribuindo aos processos de imaginação destaque na compreensão do lugar do indivíduo nos processos sociais. Esse é um aspeto que desapareceu das propostas mais radicais do construcionismo social, nas quais o sujeito foi diluído no espaço relacional, levando a um determinismo relacional.

Em suma, a psicoterapia é parte inseparável dos mais variados sistemas de ações profissionais orientados à mudança do outro. Seu caráter circunscrito à clínica individual e à ausência de ações dialógicas orientadas ao modo de vida foram expressão de três aspectos fundamentais: (1) a fragmentação das áreas de atuação profissional e das teorias em psicologia; (2) a ausência de teorias que compreendessem o caráter subjetivo da ação e (3) a mercantilização da psicoterapia. Essa forma de compreender a psicoterapia levou a uma separação entre educação e psicoterapia, para além de gerar frequentes quadros de terapias indefinidas e excessivamente prolongadas.

\section{A ação profissional na escola}

A escola, como toda instituição social, expressa em suas configurações subjetivas sociais muitas das representações, discursos e crenças da subjetividade social dominante do país no qual se insere. No Brasil, o discurso patologizante em relação às dificuldades escolares tem ganhado enorme espaço nas duas últimas décadas. $\mathrm{Na}$ linha de trabalho de nosso grupo (GONZALEZ REY, 2011; MITJÁNS MARTÍNEZ, 2005, 2009), destacam-se duas importantes pesquisas orientadas à ação profissional do psicólogo na escola com crianças que apresentam dificuldades escolares: a de Rossato (2009) e a de Bezerra (2014). Em ambas as pesquisas, o trabalho foi realizado, simultaneamente, com as crianças, os professores e as famílias dos alunos com dificuldades escolares.

Escolhemos o caso de Kevin para este artigo, trabalhado por Bezerra (2014). Kevin cursava o segundo grau de ensino fundamental, era um menino tímido, que apresentava sérias dificuldades de aprendizagem. As professoras de Kevin não pareciam se esforçar para se comunicarem com ele, nem facilitavam o contato de Kevin com o resto dos meninos do grupo. O que era permanentemente enfatizado eram suas "dificuldades de aprendizagem". As professoras tampouco davam atenção a como essas dificuldades da vida emocional e social da criança afetavam o seu rendimento escolar.

É marcante a carência de políticas educativas relacionadas à condição social e aos processos subjetivos de estudantes com dificuldades de aprendizagem. Pais alcoolistas, ausentes, violentos, indiferentes, ou inexistência de vínculos afetivos na escola são algumas das experiências vividas por muitas crianças que apresentam problemas de aprendizagem no Brasil. Porém, esses problemas de aprendizagem são considerados transtornos individuais das crianças a serem tratados pela medicina.

Kevin morava em um pequeno local em um prédio comercial com a mãe e uma irmã de 17 anos. O aluguel era pago através de um programa de assistência social. O pai abandonou a casa quando Kevin tinha seis anos e a mãe encontrava-se desempregada. Ele não tinha amigos, nem pode brincar fora de casa por questões de segurança. De modo geral, ele praticamente não tem atividades de lazer.

No começo do trabalho, a pesquisadora participou do cotidiano de sua sala de aula e seu maior interesse foi compreender como a classe funcionava e como estava organizado o trabalho pedagógico. Na segunda semana na escola, Kevin se aproximou espontaneamente da pesquisadora e perguntou se podia contar uma história para ela. De forma afetiva, ela respondeu: "claro que sim".

Kevin expressou curiosidade pela presença da pesquisadora em sala de aula desde seu primeiro dia ali. Apesar de sua timidez, ele encontrou um modo de ficar perto da pesquisadora em sala. Essa aproximação espontânea da criança está relacionada à expressão aberta e afetiva da pesquisadora para as crianças da sala. 
A história contada em detalhes por ele foi a mesma que a professora tinha contado para o grupo no dia anterior, quando Kevin, segundo notas da pesquisadora, parecia distraído, ausente e perdido no curso da atividade, enquanto as outras crianças participavam ativamente da atividade.

Kevin estava concentrado e interessado em contar a história completa como forma de ser reconhecido pela pesquisadora e de se sentir aceito, oportunidade que não lhe foi oferecida pela professora em sala de aula. Seu envolvimento na narração da história foi tal que, em determinado momento, outro aluno da sala se aproximou deles, mas Kevin pediu a ele para esperar sua vez de falar, para não interromper sua história. Esse posicionamento do aluno é um forte indicador de como ele desejava ter um interlocutor, alguém que se interessasse por ele e a quem ele pudesse demonstrar como era capaz de realizar as atividades em sala.

A partir da criação desse espaço social dialógico entre a pesquisadora e a criança, a pesquisadora passou a acompanhar Kevin individualmente, o que representou um processo psicoterapêutico desenvolvido no campo da pesquisa. Os encontros, a pedido da criança, iniciavam-se com a leitura de um conto infantil e encerravam-se com uma rodada de jogo da memória, quebra-cabeça, ou outro jogo escolhido pela criança. Foi em um desses momentos, na leitura de um conto e explorando as ilustrações contidas no livro, que Kevin demonstrou dificuldades em nomear algumas frutas consideradas comuns para a maioria das pessoas. Diante dessa situação, a pesquisadora viu a oportunidade de explorar outros espaços, com o intuito de retomar o movimento e a circulação social, prejudicadas pelo excesso de proteção da família e pelo processo de institucionalização no contexto escolar que Kevin estava envolvido. Nesse sentido, o setting empírico ganhou o espaço da rua. A proposta feita a Kevin consistiu na realização de um passeio a um mercado próximo a sua residência.

No percurso realizado até o mercado, Kevin apontava para os letreiros na rua, reconhecendo algumas letras: "Olha Tia, a letra 'G'. Igual à do gato". Kevin demonstrou curiosidade em relação aos alimentos, se eram frutas, legumes ou verduras. Foi solicitado a Kevin que escolhesse alguns alimentos para comprá-los.

A sugestão de uma atividade mais dinâmica tinha por objetivo proporcionar a Kevin a possibilidade de vivenciar outras experiências, não cristalizadas pelo seu cotidiano. A ida ao mercado constituiu uma ação voltada para a criação de possibilidades de desenvolvimento, capaz de envolver a criança no universo cultural da aprendizagem. No encontro seguinte, uma semana após o passeio, foi realizada uma atividade relacionada à experiência vivenciada por Kevin, que consistia na elaboração de uma escrita acerca dos alimentos que a criança havia comprado. Em nosso sistema educacional, a negação do sujeito que aprende enquanto protagonista da aprendizagem acarretou a desconsideração da dimensão subjetiva envolvida nos processos produção intelectual. No percurso da atividade, Kevin expressou o descontentamento que sentia em relação aos comentários dos colegas de sala de aula.

Kevin: Tia, meus amigos dizem que eu sou burro, que não aprendo.

Pesquisadora: E o que você faz?

Kevin: Vou dizer que não sei. Mas que posso aprender.

Os sentidos subjetivos dominantes em relação aos sentimentos de medo e insegurança foram perdendo força na dinâmica subjetiva de Kevin, enquanto emergia a confiança em relação às suas possibilidades de aprendizagem, embora timidamente. Esse processo caracteriza a processualidade das produções subjetivas de Kevin, assim como o caráter gerador de suas emoções.

A produção de novos sentidos subjetivos frente às dificuldades enfrentadas por Kevin caracterizou a pesquisa como um processo de desenvolvimento subjetivo, o que permitiu a ele se reposicionar em relação aos seus medos. Os desdobramentos desses novos processos subjetivos que emergiram no curso da pesquisa não são passíveis de previsão e controle, pois são da ordem do devir, do vir a ser, sendo que nenhuma realidade concreta seria capaz de determinar um tipo de produção subjetiva e suas possíveis consequências.

Os novos sentidos subjetivos que se configuraram na relação com a pesquisadora e que transformaram essa relação na configuração subjetiva central da criança no espaço da escola é a forca dinâmica das mudanças de Kevin frente à escola e à sua aprendizagem. Este caso ilustra muito bem como as mudanças subjetivas que começam em um contexto específico se relacionam com outras áreas da vida formando um sistema em desenvolvimento.

Atualmente, muitos professores no Brasil têm perdido sua atuação educativa com as crianças, o que implica, em muitas das escolas públicas, em especial das periferias, um distanciamento entre escola e família. Devido, entre outros fatores, às regulamentações e políticas educativas, o professor tem uma atividade profissional restrita à instrução na maior parte dos casos. Esse posicionamento tem sido reforçado pelas representações dominantes dos professores sobre os fatores associados ao êxito e ao fracasso na escola, sintonizadas com a patologização das dificuldades escolares.

O trabalho profissional do psicólogo na escola exige sua presença no campo e sua atenção àqueles fatores da vida social da criança que se relacionam com produções 
subjetivas que dificultam o seu desenvolvimento subjetivo e que, portanto, estão estreitamente associadas aos transtornos relacionados com a aprendizagem. A aprendizagem não é um processo intelectual-instrumental, mas um processo subjetivo responsável pela motivação para aprender.

O afeto gerado na comunicação é essencial em qualquer atividade orientada ao desenvolvimento subjetivo da criança. Sem um espaço de socialização em que a criança se sinta acolhida e segura, o desempenho dela em qualquer atividade estará comprometido. As burocracias de medidas e tratamentos extraescolares não levam à integração social da criança no espaço da escola. Isso somente é possível com a presença ativa do profissional nos espaços sociais mais relevantes da vida da criança.

\section{A ação profissional do psicólogo nos serviços de saúde mental: superando a clínica da patologia a partir da subjetividade}

O lugar do psicólogo nas instituições de saúde, em geral, continua subordinado ao modelo biomédico de trabalho clínico. Assim, esse é o modelo de atendimento dominante nos serviços de atenção à saúde mental atualmente vigentes, como é o caso dos Centros de Atenção Psicossocial (CAPS). Apesar dos inúmeros avanços, nas últimas duas décadas, em termos da qualidade do atendimento em saúde mental prestado à população, fruto da reforma psiquiátrica no Brasil, paradoxalmente, a psiquiatria e as práticas medicamentosas continuam tendo papel central nas práticas institucionais atuais.

Partindo das posições teóricas explicitas anteriormente neste artigo, as ações orientadas à mudança e ao desenvolvimento da subjetividade não apenas podem se centrar na psicoterapia compreendida como processo dialógico relacional com o indivíduo, mas devem ir além dessa relação e atuar sobre a condição social das pessoas, seu modo de vida e o contexto dentro do qual realizam suas atividades. Neste sentido, em trabalhos anteriores (GONZÁLEZ REY, 1989, 1997, 2004, 2011), o modo de vida foi definido não apenas como conjunto de atividades realizadas pela pessoa, mas enquanto sistema subjetivo vivo que caracteriza a historicidade das experiências vividas pelos indivíduos e grupos dentro de determinada cultura: "O modo de vida na forma em que assumimos essa categoria em nossas pesquisas sobre saúde humana (GONZÁLEZ REY, 1997, 2004) é sempre uma produção subjetiva relacionada com as ações, relações e preferencias que definem em seu inter-relacionamento a forma como vivemos" (GONZÁLEZ REY, 2011, p. 40).

$\mathrm{O}$ modo de vida de usuários atendidos por uma instituição de saúde configura-se dentro do espaço institucional, o que, no campo da saúde, ainda se caracteriza por atividades prescritas pelos profissionais, não deixando espaço para atividades espontaneamente planejadas pelas pessoas em tratamento. Isso é especialmente marcante na dinâmica de serviços voltados para o trabalho com pessoas com transtornos mentais graves, como os CAPS.

O trabalho de Goulart (2013, 2015), inserido na dinâmica institucional de um CAPS, discutiu teoricamente essas questões, promovendo alternativas teóricas interessantes para refletir sobre possíveis estratégias institucionais a essas limitações atuais. Tal trabalho implicou em sua participação em múltiplas atividades no serviço, tanto com os profissionais, como com pessoas atendidas e teve como um de seus objetivos centrais, a promoção do desenvolvimento da subjetividade dos usuários. Tal trabalho partiu de ações conjuntas do pesquisador com os usuários, promovendo atividades que envolveram de forma espontânea os participantes atendidos pelo CAPS.

O caso Sebastiao é uma evidência dos processos de desenvolvimento subjetivo através de sua integração em atividades realizadas dentro e fora do serviço de saúde mental (GOULART, 2013). Sebastião tinha 37 anos no momento em que o pesquisador iniciou seu contato com ele. Era um homem tímido, sorridente e, de modo geral, cordial com as pessoas que o cercam. Solteiro, não possuía filhos e, ao longo de sua vida, sempre morou com outros familiares. Era diagnosticado, desde os 30 anos, com esquizofrenia paranoide, tendo passado por duas internações psiquiátricas e fazendo uso regular de psicotrópicos desde então. Sebastião era conhecido entre os profissionais como um dos primeiros usuários do serviço, com um tratamento ininterrupto de 7 anos. Algo que caracterizava sua rotina era a grande carência de espaços de socialização e de atividades fora de casa e do CAPS. Como ele mesmo afirma, seu dia-a-dia era basicamente "do quarto para o CAPS, do CAPS para o quarto".

Em uma das sessões grupais oferecidas pelo serviço, Sebastião disse:
A coisa que mais me incomoda de todas é quando alguém que nem me conhece tanto assim olha pra mim e diz: "Você tá é bom, não tem nada não!". Oxe, como é que pode né? Eu não tenho essa doença porque eu quero não... Ninguém sabe como eu tô, só o psiquiatra.

Nessa fala, Sebastião reivindica o reconhecimento do próprio sofrimento, todavia, torna-se marcante a condição de colocar a figura do psiquiatra como central no conhecimento de si mesmo. Ao assumir essa postura, a "doença" parece reificada como objeto do saber técnico do outro, ocultando a relevância de suas próprias ações no curso do seu desenvolvimento. Sua responsabilidade em seu próprio processo parece, até este momento, ser 
vivenciada como seguir aquilo que foi designado pelo outro, o que indica uma postura de submissão. Essa dinâmica expressa uma lógica manicomial que ainda se faz presente em sua vida, não no formato de grades e muros, mas na forma como ele vivencia subjetivamente suas relações no serviço de saúde mental (GOULART, 2013).

A construção interpretativa de sua condição levou o pesquisador a propor diversos momentos de reflexão com a equipe profissional do serviço, buscando fomentar ideias sobre estratégias alternativas que poderiam facilitar seu desenvolvimento, ao invés de potencializar a cronificação da situação na qual ele se encontrava. Nesse sentido, atividades diferenciadas passaram a ser propostas para ele. A importância dessa iniciativa, seguramente, estava para além do cumprimento de determinada ação, mas residia na abertura para que, a partir dessa ação, novas produções subjetivas se tornassem possíveis, podendo repercutir de maneira importante em sua vida.

Como expresso anteriormente, um dos principais desafios no caso de Sebastião era romper com seu enclausuramento e iniciar novas atividades em seu cotidiano. Nesse sentido, primeiramente, foi proposto que ele participasse de um grupo de futebol, atividade que acontecia em uma quadra comunitária próxima ao serviço. Essa atividade foi proposta a partir da reflexão de que seria interessante que ele implementasse atividades fora dos muros do serviço e pudesse se relacionar com outras pessoas em outros contextos, como em um jogo, nos quais as barreiras entre "doentes" e "não doentes" não estivessem tão marcadas. À medida que essa atividade foi se tornando frequente em sua rotina, a dimensão do exercício físico foi revitalizada em sua vida e possibilitou a criação de um espaço social lúdico, a partir do qual Sebastião pôde ampliar seus laços pessoais.

A partir da atividade do futebol, Sebastião começou espontaneamente a fazer caminhadas esporádicas próximas à sua casa. Para potencializar essa iniciativa própria, foi proposto a ele que essas caminhadas alcançassem maior regularidade, de modo que ele passou a aumentar gradualmente a frequência dessa outra atividade. Além disso, começou a melhorar sua aparência, motivado pelo espaço social que essa atividade abriu para ele. Após algumas semanas, Sebastião disse:

E daí outra coisa que mudou foi que eu passei a banhar todo dia. Antes eu banhava de três em três dias. Tinha vez que eu ficava era uma semana sem banhar... e agora é todo dia. Se eu caminho duas vezes no dia, eu banho duas vezes (risos)! Eu tô melhorando muito... antes, nem fazer a barba eu fazia, nem escovar os dentes! Hoje, eu faço é todo dia (risos)!

É interessante notar como a emergência de novos sentidos subjetivos em uma atividade (no caso, no futebol), motivou a decisão de Sebastião em iniciar novas atividades, como as caminhadas. Como resultado disso, a aceitação de si mesmo aumentou, de modo que ele superou algumas barreiras subjetivas que dificultavam qualquer integração social anteriormente, como sua própria resistência em sair de casa. Esses novos recursos subjetivos expressos por Sebastião não seriam possíveis sem vontade e motivação, dois processos interrelacionados sem os quais o desenvolvimento subjetivo é impossível. Do nosso ponto de vista, a dinamização desses processos é desdobramento da configuração subjetiva que emergiu durante as atividades de Sebastião. Gradualmente, o desenvolvimento de Sebastião passou a abranger diferentes esferas de sua vida, culminando finalmente em sua alta do CAPS no qual estava em tratamento ininterrupto há sete anos.

Finalmente, no caso de Sebastião, fica claro que as prescrições psiquiátricas no âmbito da instituição não contribuíram ao seu desenvolvimento subjetivo. Somente quando ele foi apoiado por ações educativas que abriram novos espaços sociais para ele, tanto dentro como fora da instituição, é que novos sentidos subjetivos em relação à vida e a ele mesmo começaram a ser expressos em seu novo modo de sentir e refletir sobre sua experiência. Após muitos anos no serviço de saúde mental, Sebastião começou o processo de se tornar sujeito de sua vida, algo que não era parte das expectativas institucionais até então.

\section{Ação profissional na comunidade}

O conceito de comunidade na América Latina, em geral, tem sido reduzido às comunidades de populações de baixa renda, que, na maioria dos casos, são excluídas dos serviços básicos que o Estado deveria garantir. Com exceção de Cuba, onde o capitalismo não encontrou ainda uma expressão consistente no mercado imobiliário, o que ainda garante a noção de "bairro" enquanto unidade principal da organização arquitetônica das cidades cubanas, na maioria das cidades latino-americanas, as comunidades e bairros têm desaparecido em prol de prédios altos onde, com frequência, os vizinhos não se conhecem entre si, ou de zonas residenciais onde as mansões se assemelham a castelos medievais, estando uma propositalmente distante da outra. A despersonalização da vida cotidiana na América Latina e, em certo sentido, na maior parte do mundo, tem consequências importantes na vida social e no desenvolvimento subjetivo das famílias e dos indivíduos - o que ainda tem sido pouco estudado pela psicologia social.

Os estudos comunitários têm sido um exemplo de como a ideia de intervenção funcionou na psicologia. Com frequência, trabalhos definidos como de "intervenção comunitária" estiveram orientados de forma unilateral pelos parâmetros do pesquisador, que trabalha com 
grupos dentro da comunidade, mas não com a comunidade enquanto tecido social complexo formado por inúmeros sistemas de relações que integram conjunto de grupos, tanto formais quanto informais, que se articulam entre si, configurando-se subjetivamente de formas diferentes em contextos diversos.

A ação profissional nas comunidades começa com a inserção da equipe profissional na comunidade. Essa é uma inserção ativa onde a equipe busca criar relações com espaços e agentes diferentes da comunidade, dialogando sobre o propósito de sua presença nela. Algo importante desde o início de uma ação comunitária é escolher um foco de trabalho que possa ser considerado útil para os diversos grupos da comunidade. Nesse processo, líderes e agentes ativos são identificados na vida social da comunidade e se programam reuniões com os mesmos.

Essa primeira imersão da equipe técnica na comunidade tem como objetivo começar a explicar os objetivos do trabalho e conhecer de forma pessoal os vizinhos e agentes da comunidade. Com independência do objetivo central do trabalho, toda ação comunitária deve se apoiar na criação de espaços sociais de debate, a partir dos quais novas práticas no interior da comunidade possam ser derivadas. Esses espaços estarão orientados a debater e organizar formas de ação coletiva sobre problemas que afetam a comunidade e que são passiveis de solução com recursos próprios e com o apoio da equipe profissional, tais como: crianças com dificuldades na escola, adultos analfabetos, atenção e orientação a doenças crônicas, conflitos familiares, entre outros. Esse processo inicial de contatos na comunidade tem o mesmo objetivo que a criação do cenário social de pesquisa na investigação científica (GONZÁLEZ REY, 2005). Ambos estão orientados a facilitar a emergência de interlocutores interessados no trabalho, que podem se configurar como núcleos de apoio à equipe de ação profissional e/ou de pesquisa. Algo a ser negociado desde o início com os grupos de poder comunitário é que nada do que seja feito irá prejudica-los, mantendo um diálogo aberto e permanente com tais grupos no curso do trabalho realizado.

Os espaços para debater problemas aceitos e propostos pela comunidade representam um importante recurso metodológico para que as pessoas se conheçam entre si, para que emerjam os conflitos da comunidade e para que se gerem espaços de diálogo entre os participantes. É no desenvolvimento desses processos que novas opiniões começam a circular pela comunidade, novos discursos se estabelecem e novas configurações subjetivas sociais e individuais começam a se constituírem, o que representa um primeiro momento de emergência de novos sujeitos sociais e individuais capazes de gerar, com sua ação, novos momentos nos sistemas de relacionamentos e valores da comunidade.
Os espaços de vida social estão em processo constante, podendo emergir novos conflitos e desdobramentos inesperados a qualquer momento. Por isso, pretender chegar a estados ideais inspirados pela representação do mundo dos pesquisadores é algo estéril. O objetivo de um sistema de ações profissionais na comunidade é gerar novos espaços de relação com capacidade de exercer funções produtivas no desenvolvimento da comunidade, que representem novos processos de vida em seu interior. Com grande frequência, um foco de ação comunitária gera novos sistemas de relações e práticas, num processo que produz mudanças qualitativas importantes em seu funcionamento.

A provocação e a reflexão constituem-se aspectos distintivos do diálogo enquanto recurso metodológico para pesquisadores e equipes que o utilizam como principal ferramenta para sua participação nos processos comunitários. O foco do processo de ação comunitária é o reitor dos instrumentos que vão sendo gerados ao longo do trabalho. O conceito de instrumento no desenvolvimento das ações comunitárias segue os mesmos princípios da proposta de instrumentos que definimos na pesquisa qualitativa (GONZÁLEZ REY, 2002, 2005). Os instrumentos são recursos relacionais para desencadear o posicionamento do outro, de modo que, quanto mais comprometidos emocionalmente com sua participação, mais relevantes serão para as dinâmicas relacionais desenvolvidas nos diferentes espaços comunitários.

Em Cuba, realizamos um interessante projeto comunitário numa comunidade de baixa renda da Cidade de Havana, o bairro dos Pocitos em Marianao, uma importante região da capital. Nesse projeto, participaram 12 professores e 50 estudantes. A comunidade era qualificada como muito perigosa pelo número de incidentes violentos que aconteciam e pelo número de moradores que estavam foragidos da justiça. Foi interessante o fato de nossa entrada na comunidade ter ocorrido com grupos pequenos de alunos, coordenados por um professor, que foram batendo nas portas das casas e convidando os moradores para participarem de uma reunião inicial sobre o projeto. Também, houve visitas nas escolas e postos de saúde da comunidade, além de reuniões com professores e médicos que trabalhavam em ambos os espaços institucionais. Essas reuniões visavam conhecer três questões concretas: (1) os principais problemas que enfrentavam na comunidade para o desenvolvimento de suas funções; (2) conhecer mais sobre a comunidade a partir de dois atores importantes dentro dela; (3) solicitar o apoio deles para estender e divulgar o projeto dentro da comunidade.

Observamos que instituições públicas que tinham presença na área não possuíam nenhum plano para 
se relacionar com a comunidade. Cada instituição centrava-se de forma estreita no foco de seu trabalho: ensinar, atender problemas de saúde e realizar atividades culturais em sua sede, sem que tais atividades fossem divulgadas na comunidade. As exceções em relação a esses posicionamentos eram resultado do interesse e compromisso de profissionais de forma individual.

No curso do trabalho, foram sendo criados grupos de ações profissionais na escola, que trabalhavam com os alunos com problemas de aprendizagem, com os professores e com os pais. A escola se converteu num centro de trabalho geral da comunidade, onde se realizavam diferentes foros sociais convocados durante o trabalho.

$\mathrm{Na}$ organização do trabalho, foram sendo gerados objetivos específicos dirigidos ao trabalho dentro das instituições estatais importantes na comunidade: a escola, o posto de saúde e a casa de cultura, o que se complementou com os foros de debate de assuntos definidos pelo interesse da comunidade, constituindose em novo espaço de integração entre os moradores. Novos tecidos e atores sociais iam emergindo, muitos dos quais se converteram em agentes do trabalho na comunidade. Todas as ações empreendidas tinham um caráter educativo orientado a facilitar novas formas de relação, novos espaços de convivência e novas formas de gerir os conflitos - processos que foram tomando sua própria forma dentro dos espaços criados.

Uma parte importante do projeto foi criar relações com instâncias do Estado e do Partido Comunista nos âmbitos municipal e provincial, para tentar participar nas propostas orientadas sobre o uso dos recursos destinados a comunidade. Entretanto, o caráter vertical das políticas do Estado regulamentava de forma burocrática e pouco participativa o que se realizava na comunidade, sendo impossível cumprir esse objetivo.

Essa experiência representou um modelo teórico interessante para o trabalho na comunidade que infelizmente não teve continuidade pelas crescentes dificuldades sociais e econômicas no início da década de 1990 em Cuba, quando era impossível até o traslado da equipe à comunidade por falta de transporte. Além disso, houve visível desinteresse das instâncias do Partido Comunista e do Estado para a continuação dessa experiência.

O trabalho simultâneo no desenvolvimento de novas formas de subjetivação que permita a emergência de novos sujeitos sociais e individuais na comunidade, processos que são estreitamente associados à emergência de novos tecidos sociais no interior de uma comunidade, devem culminar em novas formas de relação com outras instâncias estatais e da sociedade civil - objetivo importante de todo sistema profissional de ação comunitária. O diálogo e o respeito pelas tradições e valores locais da comunidade são aspectos essenciais para o sucesso de um sistema de ações profissionais comunitárias. Dialoga-se a partir do lugar autêntico do outro na comunicação com os profissionais/ pesquisadores e será nesse diálogo que novas formas de convivência e projetos de ação irão emergir.

\section{Algumas ReFleXões finAis.}

A subjetividade, como definida neste artigo, representa uma construção teórica com implicações para as diferentes áreas de prática profissional das ciências sociais e da psicologia em particular. O caráter configuracional complexo, que caracteriza a subjetividade como produção humana e não como reflexo das circunstâncias, implica transcender os esquemas centrados no saber do profissional, que se concretizam em formas de explicar, modelar e transformar o comportamento a partir de um referencial externo aos sujeitos envolvidos nas diferentes práticas profissionais da psicologia. A partir da teoria da subjetividade, o saber do pesquisador é apenas um recurso que alimenta as hipóteses sobre as quais se orientam ações profissionais de caráter dialógico, que visam à emergência do outro como sujeito de seus posicionamentos. Os sujeitos, assim como suas configurações subjetivas, emergem de forma simultânea nos indivíduos e nas diferentes instâncias sociais em que se organiza sua vida social.

Os processos de mudança do outro, em qualquer prática profissional, configuram-se de forma tensa e contraditória no curso da prática, com desdobramentos e formas de comportamento imprevisíveis para o próprio profissional que a conduz. Nessa perspectiva, o profissional deve aceitar o desafio de se comunicar com o outro a partir do lugar que esse outro assume em cada momento da ação profissional. A mudança da subjetividade acontece de forma processual, a partir de múltiplos momentos e encadeamentos.

A ação profissional não é uma consequência direta de uma teoria. Toda prática profissional implica sistemas diversos de ações e princípios que transformam os posicionamentos mais gerais de uma teoria em formas de ação para a prática profissional. Os interesses no lucro que orientam hoje a prática profissional na América Latina, e que se concretizam particularmente na esfera privada, dificulta uma prática social mais abrangente e comprometida com os direitos da população. Essa privatização da prática gera efeitos perversos, como a omissão de modelos orientados a uma prática comprometida com o desenvolvimento individual e social.

As diferentes formas de ação profissional apresentadas neste artigo são completamente compatíveis entre si 
e passiveis de serem realizada no interior de qualquer instituição ou comunidade. Todas as práticas profissionais devem ser orientadas a estimular o desenvolvimento humano. A atividade das ciências sociais deve preparar para a vida, não apenas para a realização ou posicionamento parcial frente a problemas específicos.

\section{REFERÊNCIAS}

BEZERRA, Marília Santos. Dificuldades de aprendizagem e subjetividade: Para além das representações hegemônicas do aprender. Dissertação (Mestrado em Educação) - Programa de Pós-Graduação em Educação, Universidade de Brasília, Brasília, 2014.

BLEICHMAR, Silvia. Conceptualización de catástrofe social: límites y encrucijadas. In: WAISBROT, D.; WIKINSKI, M.; SLUCKI, D.; TOPOROSI, S. (Org.). Clínica psicoanálitica ante las catástrofes sociales: la experiencia argentina. Buenos Aires: Paidos, 2003. p. 35-51.

DANIELS, Harry. Changing situations and motives. In: HEDEGAARD, M.; EDWARDS, A.; FLEER, M. (Org.). Motives in children development: cultural historical approaches. London: Cambridge University Press, 2012. p. 191-208.

FLEER, Marilyn. Conceptual play: foregrounding imagination and cognition during concept formation in early years education. Contemporary Issues in Early Childhood, v. 12, n. 3, p. 224 237, 2011. https://doi.org/10.2304/ciec.2011.12.3.224

FLEER, Marilyn. The development of motives in children's play. In: HEDEGAARD, M.; EDWARDS, A.; FLEER, M. (Org.). Motives in children development: cultural historical approaches. London: Cambridge University Press, 2012. p. 79-96.

GONZÁLEZ REY, Fernando. Relación entre la metodología, la teoría y la investigación empírica en el estudio de la personalidad. Journal de Psicología, v. 10, n. 6, p. 21-42, 1989.

GONZÁLEZ REY, Fernando. Psicoterapia y Personalidad: algunas reflexiones. Revista Cubana de Psicología, v. VII, p. 117-127, 1990.

GONZÁLEZ REY, Fernando. Personalidad, salud y modo de vida. México: UNAM Campus Iztacala, 1993.

GONZÁLEZ REY, Fernando. Epistemología cualitativa y subjetividad. São Paulo. EDUC, 1997.

GONZÁLEZ REY, Fernando. Saúde e subjetividade: desafios para a investigação em psicologia da saúde. Universistas Psicológica, Brasilia, v. 1, n. 1, p. 25-44, 2000.

GONZÁLEZ REY, Fernando. Sujeto y subjetividad: una aproximación histórico-cultural. México: D. F. Editora Thomson, 2002.

GONZÁleZ ReY, Fernando. Personalidade Saúde e Modo de Vida. São Paulo. Thomson, 2004.

GONZÁlEZ REY, Fernando. Pesquisa qualitativa e subjetividade: os processos de construção da informação. São Paulo: Thomson Learning, 2005.

GONZÁLEZ REY, Fernando. Psicoterapia, subjetividade e pós-modernidade: uma aproximação histórico-cultural. São Paulo: Thomson Learning, 2007.
GONZÁLEZ REY, Fernando. Subjetividade e saúde: superando a clínica da patologia. São Paulo: Cortez Editora, 2011.

GONZÁLEZ REY, Fernando. Advancing on the concept of sense: subjective and subjective configurations in human development. In: HEDEGAARD, M.; EDWARDS, A.; FLEER, M. (Org.). Motives in children development: cultural historical approaches. London: Cambridge University Press, 2012. p. $45-62$.

GONZÁLEZ REY, Fernando. Human motivation in question: discussing emotions, motives and subjectivity from a culturalhistorical standpoint. Journal for the Theory of Social Behavior, v. 45, n. 3, p. 1-18, 2014. https://doi.org/10.1111/ jtsb. 12073

GOULART, Daniel Magalhães. Institucionalização, subjetividade e desenvolvimento humano: Abrindo caminhos entre educação e saúde mental. Dissertação (Mestrado em Educação) - Programa de Pós-Graduação em Educação, Universidade de Brasília, Brasília, 2013.

GOULART, Daniel Magalhães. Clínica, subjetividade e educação: uma integração teórica alternativa para forjar uma ética do sujeito no campo da saúde mental. In: GONZÁLEZ REY, F.; BIZERRIL, J. (Org.). Saúde, cultura e subjetividade: uma referência interdisciplinary. Brasília: UniCEUB, 2015. p. 34-57.

HEDEGAARD, Mariane. The dynamic aspects in children's learning and development. In: HEDEGAARD, M.; EDWARDS, A.; FLEER, M. (Org.). Motives in children development: cultural historical approaches. London: Cambridge University Press, 2012. p. 9-27.

LEONTIEV, Alexei Nikolaevich. Deyatelnosti, Soznaniye, Lischnosti [Atividade, consciência, personalidade]. Moscou: Politizdat, 1975.

MIASICHEV, V. N. Lischnost e nevrozy [A personalidade e a neurose]. Leningrado: Editora Universidade de Leningrado, 1960.

MITJÁNS MARTÍNEZ, Albertina. La escuela como organización: sus possibilidades creativas y inovadoras. Revista Linhas Críticas, v. 1, n. 8, p. 45-56, 1999.

MITJÁNS MARTÍNEZ, Albertina. Inclusão escolar: desafios para o psicólogo. In: MITJÁNS MARTINEZ, A. (Org.). Psicologia Escolar e compromisso social. Campinas: Alínea, 2005, p. 105-127.

MITJÁNS MARTÍNEZ, Albertina. La perspectiva históricocultural y la educación especial: contribuciones iniciales y desarrollos actuales. Actualidades Investigativas en Educación, v. 9, n. esp., p. 1-28, 2009.

MOLL, Luis. Only life educates: Immigrant families, the cultivation of bileteracy, and the mobility of knowledge. In: PORTES, P.; SALAS, S. (Org.). Vygotsky in the 21st century society: advances in cultural historical theory and praxis with non-dominant communities. New York: Peter Lang, 2011. p. 151-161.

PORTES, Pedro. Vygorsky's significance in advancing counseling and psychoterapy. In: PORTES, P.; SALAS, S. (Orgs.). Vygotsky in the 21 st century society. New York: Peter Lang, 2011, p. 113-130.

ROSSATO, Maristela. O movimento da subjetividade na superação das dificuldades de aprendizagem. Tese (Doutorado em Educação) - Programa de Pós-Graduação em Educação, Universidade de Brasília, Brasília, 2009. 
VASILYUK, Fedor. Coexperiencing psychoterapy as a psychotechnical system. Journal of Russian and East European Psychology, v. 52, n. 1, p. 1-58, 2015. https://doi.or g/10.1080/10610405.2015.1064721

YASNITSKY, Anton. Vygotsky circle during the decades of 1931-1934: Toward an integrative science of mind, brain and education. Tese (Doutorado) - Department of Curriculum, Teaching and Learning, University of Toronto, Toronto, 2009.
YASNITSKY, Anton. Revisionist revolution in Vygotskian science: toward cultural-historical Gestalt psychology. Journal of Russian and East European Psychology, v. 50, p. 3-15, 2012. https://doi.org/10.2753/RPO1061-0405500400

Submetido em 23/06/2016

Aprovado em 20/10/2016 